\title{
Stakeholder analysis of childhood obesity prevention policies in Iran
}

\author{
Shahnaz Taghizadeh ${ }^{1}$ (D), Rahim Khodayari Zarnag ${ }^{2}$ (D) and Mahdieh Abbasalizad Farhangi ${ }^{3^{*}}$
}

\begin{abstract}
Background: Childhood obesity is one of the most serious health challenges and risk factors for various diseases. International health organizations, such as the World Health Organization (WHO), recommend more stakeholder engagement to discuss this health problem. Therefore, this study aims to identify and analyze the stakeholders of childhood obesity prevention (COP) policy making process in Iran.

Methods: In this study, semi-structured interviews were conducted with 24 Iranian stakeholders in the field of COP from February 2019 to May 2020. PolicyMaker V.4 and MAXQDA V.10 software were used for the analysis of stakeholders.

Results: Out of 24 interviewed stakeholders, 17 were active and seven were inactive. The most powerful and supportive stakeholders were the Ministry of Health and Medical Education (MoHME) and the national and regional Offices of Community Nutrition Improvement. Although stakeholders like the Ministry of Sports and Youth, the municipalities, the Secretariat of the Health and Food Safety, the Islamic Republic of Iran Broadcasting (IRIB), and Student Organization were among powerful bodies, they showed the least support for COP policies. The remaining stakeholders showed medium or low support and power in the policy making process.

Conclusions: Disconnect between stakeholders, less attention to prevention strategies, and high advertising of unhealthy foods were among the main challenges facing the COP policies in Iran and worldwide. Insufficient financial resources, little attention to the young people under 18, non-aligned policies of the Student Organization and the IRIB, and insufficient support of COP policies were among the key challenges to be handled.
\end{abstract}

Keywords: Stakeholder analysis, Childhood obesity, Prevention, Policy

\section{Background}

Childhood obesity is one of the most serious health challenges and risk factors for cardiovascular, metabolic, gastrointestinal, and other diseases [1]. According to the report by the World Health Organization (WHO), 40 million children under the age of 5 were overweight or obese in 2018 and over 340 million children and adolescents aged 5-19 were overweight or obese in 2016 [2]. Meanwhile, the rate of childhood obesity in developing countries was $30 \%$ higher than in developed countries [3].

\footnotetext{
* Correspondence: abbasalizad_m@yahoo.com; abbasalizadm@tbzmed.ac.ir ${ }^{3}$ Department of Community Nutrition, Nutrition Faculty, Tabriz University of Medical Sciences, POBOX: 14711, Attar Nishabouri St., Tabriz 5166614711, Iran Full list of author information is available at the end of the article
}

The results of a surveillance study entitled "Childhood and Adolescence Surveillance and Prevention of Adult Noncommunicable Disease" (CASPIAN-V) conducted on 14, 118 subjects aged 7-18 years in 30 provinces of Iran showed that the prevalence of overweight and obesity was 9.4 and $11.4 \%$, respectively [4]. Several previous studies showed that the upward trend of childhood obesity will impose high costs on the health system and will have irreparable consequences for the individuals and society $[5,6]$. Many factors such as consuming more energetic foods or lack of physical activity (PA) can affect the prevalence of obesity in this age group [7, 8]. In a metaanalysis, Norris et al. demonstrated that PA in schools significantly improved students' academic performance and had a positive effect on health [9]. Moreover, the CASP

(c) The Author(s). 2021 Open Access This article is licensed under a Creative Commons Attribution 4.0 International License, which permits use, sharing, adaptation, distribution and reproduction in any medium or format, as long as you give appropriate credit to the original author(s) and the source, provide a link to the Creative Commons licence, and indicate if changes were made. The images or other third party material in this article are included in the article's Creative Commons licence, unless indicated otherwise in a credit line to the material. If material is not included in the article's Creative Commons licence and your intended use is not permitted by statutory regulation or exceeds the permitted use, you will need to obtain permission directly from the copyright holder. To view a copy of this licence, visit http://creativecommons.org/licenses/by/4.0/ The Creative Commons Public Domain Dedication waiver (http://creativecommons.org/publicdomain/zero/1.0/) applies to the data made available in this article, unless otherwise stated in a credit line to the data. 
IAN-V study carried out in 2014 showed that $58 \%$ of children and adolescents had a low level of PA and 53.6\% of them had a low or moderate adherence to healthy nutritional behaviors [10].

Accordingly, the WHO advises governments to take population-based strategies to combat obesity in children and adolescents [11]. Due to the increasing prevalence of childhood inactivity among different countries of the world, the WHO developed a plan in 2018 to increase PA among young people under 18. Therefore, different organizations and stakeholders should make appropriate policies in this respect. Studies show that, similar to other countries [12], there are conflicts of interest among stakeholders in the healthcare system and that health priorities are not prioritized properly in Iran [13]. Adhikari et al. evaluated the Malawian health system stakeholders and showed that having problems in coordinating between stakeholders would create many problems for health system policies [14]. Regarding the dominance of a curative approach over preventive approach in Iran [13], it seems that the analysis of stakeholders is important for future policies related to childhood obesity prevention (COP). In this regard, the results of a study in Brunei to check the strengths and weaknesses of COP policies through semi-structured interviews with the government and school stakeholders indicated that most stakeholders blamed parents for the problem of childhood obesity. This individualization of the problem from the perspective of stakeholders was identified as a barrier to the planning and implementation of relevant COP interventions [15]. As far as the researchers investigated, so far, no comprehensive study has been carried out to identify the role of key stakeholders and actors related to COP in Iran. Therefore, this study aims to identify and evaluate the stakeholders of COP policy making process in Iran.

\section{Materials and methods}

In-depth, semi-structured, one-to-one interviews were used to explore the perceptions of stakeholders of the COP policies in Iran. This qualitative stakeholder analysis is part of a larger qualitative exploratory study entitled "A Future Study and Policy Analysis of the Prevention of Obesity in Children and Adolescents in Iran and Providing Policy Options". The study setting was on the organizations and institutions involved in Iran's COP policies. Policy, as used in this study, refers to any national, regional, or local program, law, regulation, or rule related to COP [16]. Key informants were identified as targeted sampling method; over time, using snowball sampling method, interviews were conducted up to the data saturation. Finally, 24 key informants were interviewed. The aims of the study were provided to all participants and a consent was obtained from them. To make participants at ease when answering the questions, the anonymity of all data was assured.

PolicyMaker software V.4 was used in the analysis process; this software has been designed by Harvard University and organizes stakeholder information, provides guidance on strategies to deal with the stakeholders, and creates effective visuals for presenting the information to policymakers [16]. Following the recommendations by WHO in the analysis of stakeholders, the MAXQDA V.10 software and Kammi Schmeer model [16] were used for designing and implementing the study. As can be seen in Table 1, there were eight stages in current study.

\section{Results}

In this study, 24 informants were interviewed and 3 stakeholders (General Directorate of Standards, Regional Broadcasting Organization, and Department of Economic Affairs and Finance) rejected our invitation to participate in the interviews (response rate $=88.8 \%$ ). The general characteristics of the stakeholders were as follows: there were eight policymakers and 16 executive managers (12 women and $12 \mathrm{men})$. The average work experience of stakeholders was 14.65 years and their average age was 47.86 years old. The results were categorized into nine sections and stakeholders' analysis findings were presented based on the results of the document analysis and interviews. The characteristics of participants and their positions are shown in Table 2. The key stakeholders were analyzed according to the stakeholder analysis guidelines. PolicyMaker software (version 4) was also used to assess stakeholder characteristics more accurately [16].

\section{Identification of stakeholders}

\section{Introducing some organizations of the stakeholders}

In this section, a brief description of some organizations that may be unfamiliar to the readers is presented; then the results of this study are discussed.

According to the latest information, Iran is divided into 31 provinces and each province into several cities. There are 1240 Municipalities in Iran. Each city has a main municipality and large cities have several regional municipalities. The municipalities are a public, nongovernmental, local, and self-sufficient organizations, and their major source of income is through collecting taxes and tolls from the citizens. Cities with more than 200,000 people are divided into different areas (regional) $[17,18]$. The municipalities are responsible for facilitating safe and suitable places for PA in parks or in the cities, which can be effective in obesity prevention [19].

The Welfare Organization of Iran is a government agency and sector of the Ministry of Welfare and Social Security of Iran. Part of the responsibilities of this organization is to license and manage kindergartens for people under the age 
Table 1 The process of stakeholder's analysis in childhood obesity prevention policies

\begin{tabular}{|c|c|c|}
\hline stage & Name of stage & Processes of each stage \\
\hline First stage & Planning the process & $\begin{array}{l}\text { - Formation three sessions working group } \\
\text { - Definition the purpose of the analysis, determining the approximate timeline, how } \\
\text { to conduct the interview process, determining the goals and how to use the results } \\
\text { during the sessions } \\
\text { - Review relevant website, documents and articles }\end{array}$ \\
\hline Second stage & Selecting and defining a policy & $\begin{array}{l}\text { - Consulted a number of policy makers (to define child and adolescent obesity } \\
\text { prevention policies) } \\
\text { - Coordination meeting with the research team }\end{array}$ \\
\hline Third stage & Identifying key stakeholders & $\begin{array}{l}\text { - Develop the priority stakeholders list with possible to be added in the next steps as } \\
\text { snowballs }\end{array}$ \\
\hline Forth stage & Adapting the tools & $\begin{array}{l}\text { - Developed a standard questionnaire (open-end) for interviewing stakeholders } \\
\text { - Review existing information from possible sources (e.g. newspapers, institutional } \\
\text { reports and publications, websites and other available documents) } \\
\text { - Develop the interview protocol: (conducted as pretest the interview guideline with } \\
4 \text { nonpriority stakeholders to determine the comfortable, understands the questions } \\
\text { and the time line of interviews) }\end{array}$ \\
\hline Fifth stage & $\begin{array}{l}\text { Collecting and recording } \\
\text { the information }\end{array}$ & $\begin{array}{l}\text { - Conducting interviews (after previous coordination) } \\
\text { - Created a separate electronic file for each stakeholder } \\
\text { - Enter the stakeholder's answers for each question into the computer (immediately } \\
\text { following the interview) }\end{array}$ \\
\hline Sixth stage & Filling in the stakeholder table & $\begin{array}{l}\text { - Transferred the interview responses to the table (using the completed interview } \\
\text { guidelines and electronic files for each of stakeholders) }\end{array}$ \\
\hline Seventh stage & Analyzing the stakeholder table & $\begin{array}{l}\text { - Analyze the findings in the results of interviews using policy maker and } \\
\text { MAXQDA10 software. } \\
\text { - Divide the stakeholders into nine groups which are shown in the form of a matrix } \\
\text { in Table } 3 .\end{array}$ \\
\hline Eighth stage & Using the information & $\begin{array}{l}\text { - The results of the analysis were collected so that it could be used in various areas } \\
\text { such as action plans to increase support for a reform policy, policymakers and } \\
\text { policy providers }\end{array}$ \\
\hline
\end{tabular}

of 6 in the country. In addition, one of the duties of this organization is to teach healthy lifestyles to children and parents. Since 2007, a warm meal per day is provided to the students at rural kindergartens, which is implemented by the Welfare Organization; and nutrition education is one of the goals of this program [20].

The Student Organization is a public and nongovernmental organization affiliated to the Ministry of Education (MoE); however, it is not a subset of the MoE. Strengthening social education and planning for students' leisure times is one of the most important goals of this organization. One of the tasks of this organization is to monitor the quantity and quality of food products or snacks sold in school canteens (buffets). Buffets are more like a kiosk, where students buy snacks such as cakes and biscuits. It is necessary to mention that, the buffets are available in both public and private schools; but in most private schools, some warm foods such as pasta, soup, etc. are also provided. The distribution of these warm foods is not the responsibility of the Student Organization and the schools are responsible for preparing and distributing these foods.

\section{The present and absent stakeholders}

Given the multifaceted nature of COP policies, many stakeholders at the levels of prevention and support can involve in related policies and programs. Based on the existing documents and supplementary views of the key informants, the findings of current study showed that several stakeholders do not have significant and clear roles in childhood and adolescent obesity prevention programs despite their high potentials in this respect. We categorized these stakeholders as absent (A), and the rest of the stakeholders that were somehow involved in the policies, though to a small extent, as present (P) stakeholders (Table 2).

\section{Characteristics of the stakeholders}

As Table 2 shows, the characteristics of the stakeholders are presented in eight areas. The level of stakeholders is divided into two national or regional levels. Among the stakeholders interviewed, eight stakeholders were national and 16 were regional. Given that having the power to participate and support the policies is very important, we examined the level of support from stakeholders in power. Table 3 shows the impact of power and position of stakeholders in the process of policymaking; we have also described the position of stakeholders with high power in detail. It should be noted that in the PolicyMaker software, the level of support for the policies refers to the stakeholders' approach, perspective, and 


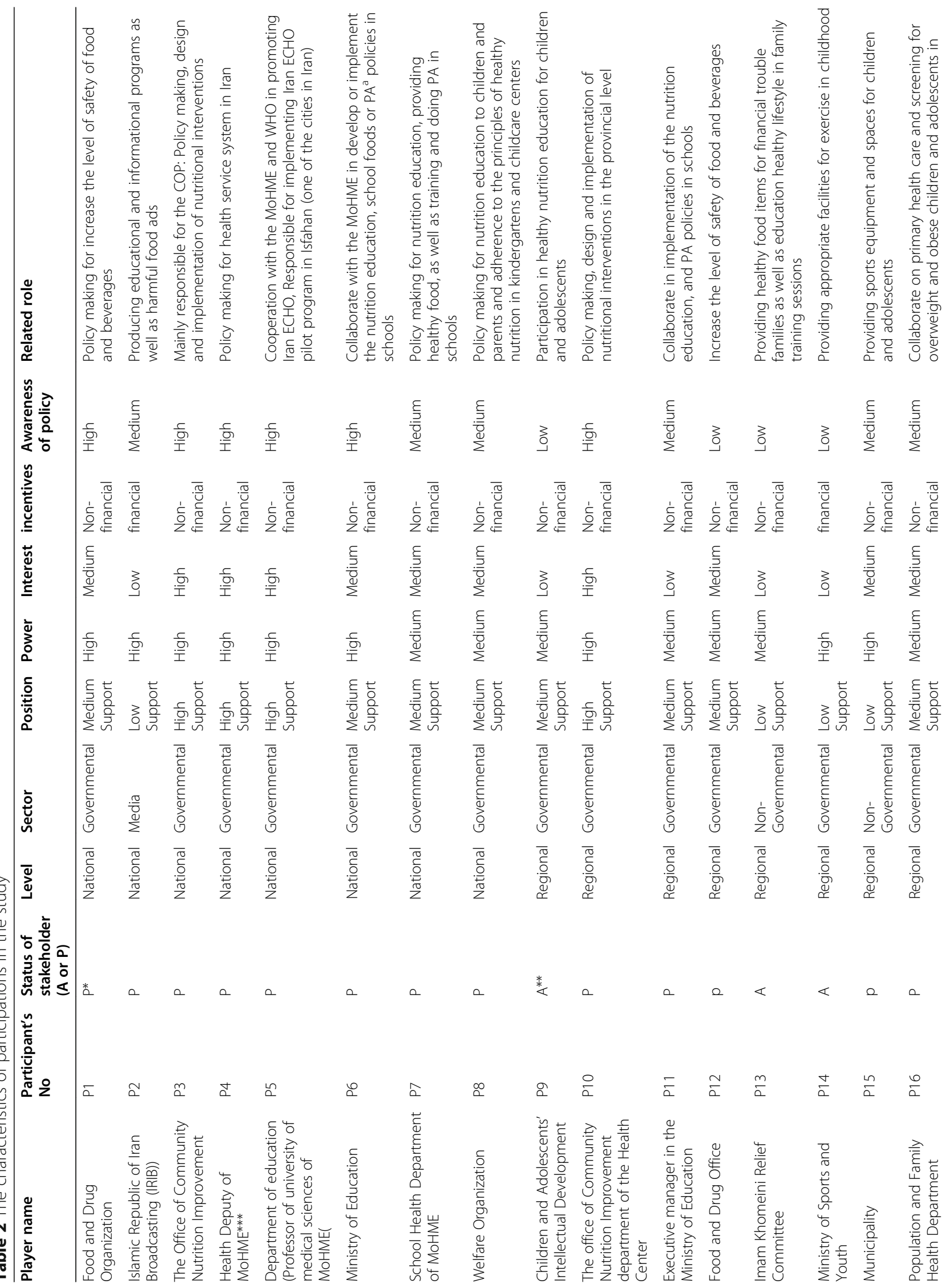




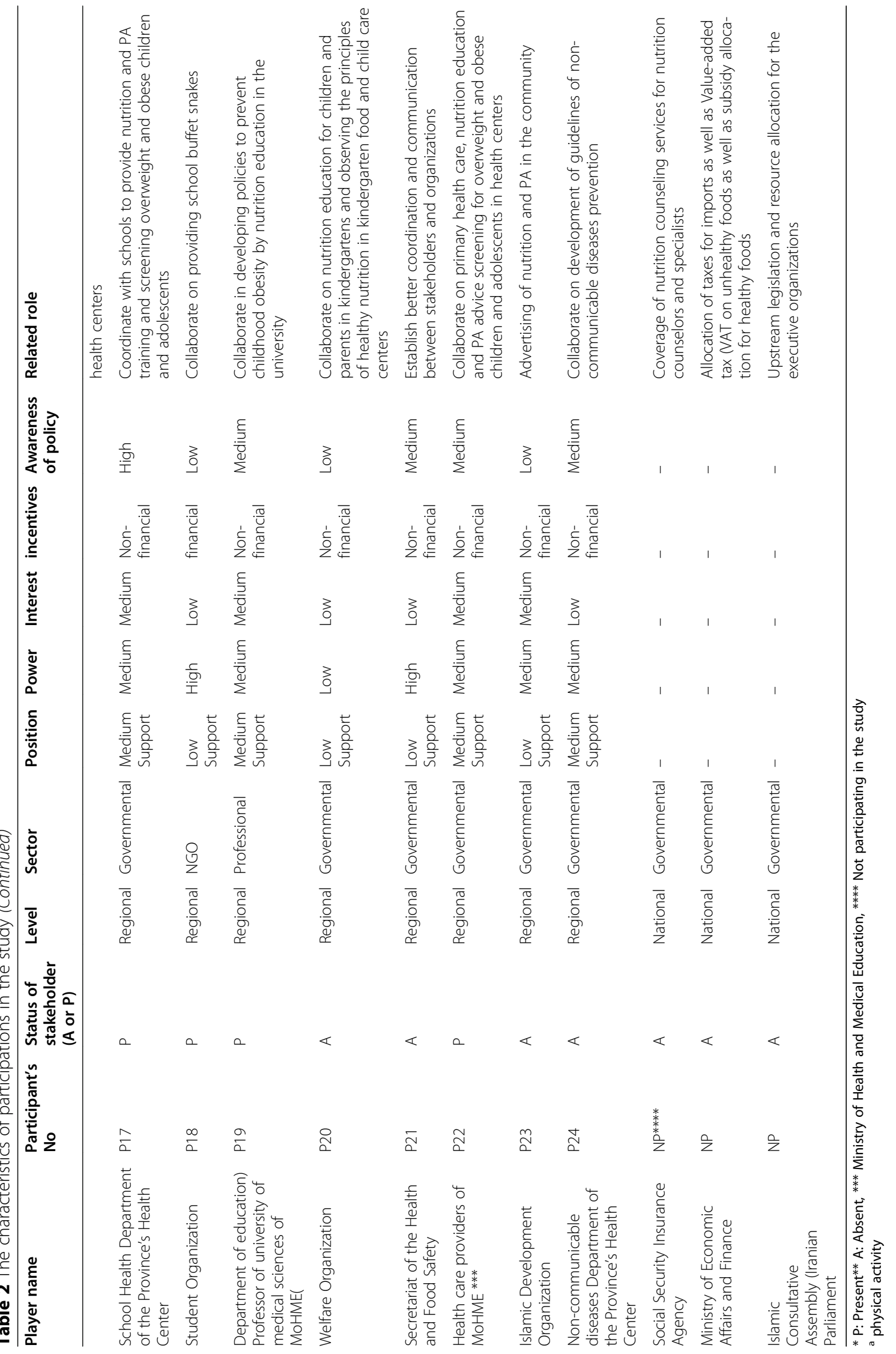


Table 3 Estimation of position and power of childhood obesity prevention policies in Iran (in 2020)

\begin{tabular}{|c|c|c|c|c|}
\hline \multicolumn{5}{|l|}{ POWER } \\
\hline \multicolumn{2}{|l|}{ POSITION } & Low & Medium & High \\
\hline & $\begin{array}{l}\text { High } \\
\text { supportive }\end{array}$ & - & - & $\begin{array}{l}\checkmark \text { The Office of Community Nutrition } \\
\text { Improvement }\left(\mathrm{N}^{*}\right) \\
\checkmark \text { The Office of Community Nutrition } \\
\text { Improvement Department of the } \\
\text { Health Center }\left(\mathrm{R}^{* *}\right) \\
\checkmark \text { Health deputy of MoHME }{ }^{* * *}\left(\mathrm{~N}^{*}\right)\end{array}$ \\
\hline & $\begin{array}{l}\text { Medium } \\
\text { supportive }\end{array}$ & - & $\begin{array}{l}\checkmark \text { School Health Department of MoHME }\left(\mathrm{N}^{*}\right) \\
\checkmark \text { Welfare Organization }\left(\mathrm{N}^{*}\right) \\
\checkmark \text { Children and Adolescents Intellectual } \\
\text { Development }\left(\mathrm{R}^{* *}\right) \\
\checkmark \text { Population and Family Health Department }\left(\mathrm{R}^{* *}\right) \\
\checkmark \text { School Health Department of Health } \\
\text { Center }\left(\mathrm{R}^{* *}\right) \\
\checkmark \text { Department of education, university of medical } \\
\text { sciences }{ }^{\mathrm{a}}\left(\mathrm{R}^{* *}\right) \\
\checkmark \text { Health care providers of MoHME }\left(\mathrm{R}^{* *}\right) \\
\checkmark \text { Executive manager in the Ministry of } \\
\text { Education }\left(\mathrm{R}^{* *}\right) \\
\checkmark \text { Food and Drug Office }\left(\mathrm{R}^{* *}\right)\end{array}$ & $\begin{array}{l}\checkmark \text { Ministry of Education }\left(\mathrm{N}^{*}\right) \\
\checkmark \text { Food and Drug Organization }\left(\mathrm{N}^{*}\right)\end{array}$ \\
\hline & $\begin{array}{l}\text { Low } \\
\text { supportive }\end{array}$ & $\checkmark$ Welfare Organization & $\begin{array}{l}\checkmark \text { Imam Khomeini Relief Committee }\left(R^{* *}\right) \\
\checkmark \text { Islamic Development Organization }\left(R^{* *}\right) \\
\checkmark \text { Non-communicable diseases department } \\
\text { of the province's Health Center }\left(R^{* *}\right)\end{array}$ & $\begin{array}{l}\checkmark \text { Ministry of Sports and Youth }\left(R^{* *}\right) \\
\checkmark \text { Secretariat of the Health and Food } \\
\text { Safety } \\
\checkmark \text { Islamic Republic of Iran Broadcasting } \\
(\text { IRIB }) \text { ( }\left(N^{*}\right) \\
\checkmark \text { Student Organization }\left(R^{* *}\right) \\
\checkmark \text { Municipality }\left(R^{* *}\right)\end{array}$ \\
\hline
\end{tabular}

${ }^{*} \mathrm{~N}$ : National, ${ }^{*} \mathrm{R}$ : Regional, ${ }^{* * *}$ Ministry of Health and Medical Education, ${ }^{a}$ this stakeholder is university professor

position as well as using their power and facilities in this respect.

\section{High supportive stakeholders with high power}

The most powerful and supportive stakeholders were the Health Deputy of MoHME and the national (policymaking) and regional (policy implementation) Offices of Community Nutrition Improvement. In 2014, Iran's healthcare system took a major step in preventing noncommunicable diseases by creating a new system for providing services called Health Transformation Plan. One interviewee from the Office of Community Nutrition Improvement explained that:

"After the health transformation plan, two important things happened that are unique: one is the use of nutrition experts and the other is that the programs were integrated with the view of preventing noncommunicable diseases, obesity, and overweight" (P3).

Since 2016, the Iran ECHO (IRAN-Ending Childhood Obesity) program, which is a proposal of the WHO to end obesity in the world, has been implemented in some provinces of Iran.

\section{Medium supportive stakeholders with high power}

The medium supportive stakeholders with high power included MoE and Food and Drug Administration of the
MoHME. There are two main challenges for MoE stakeholders. Firstly, it seems that despite the high power for practical school policymaking, school-based communication policies are not properly implemented by executive managers. In addition, MoE stakeholders believe that their organization is not directly responsible for preventing obesity in children and adolescents:

"School buffets should be constantly inspected and controlled by education administrators, but it is not fulfilled appropriately" (P17).

Secondly, the follow-up at the executive level in schools is insufficient and inefficient. Physical education is not effectively implemented in schools that do not have a sports hall, especially in snowy or rainy days. In addition, some health-related policies in the MoE are often implemented inappropriately due to lack of financial resources and staff. Sport centers exist in some large public schools, that are designed to fill the leisure time of interested students, but due to poor management and the need for students to paying a fee, students do not have much desire to participate in these centers. Nutrition and health education textbook is intended for the high school (12th grade). However, the time of this course and physical education course is usually devoted to other courses required in the university entrance exam, and unfortunately, policymakers have not developed 
effective policies in this regard. Another problem in this organization is the inadequacy of sports equipment in schools as well as, physical education teachers in primary schools.

The Food and Drug Administration of the MoHME has designed plans to prevent obesity in the community including: $10 \%$ reduction in the sugar content of carbonated beverages since 2015, reduction of trans fatty acids in edible oils from $58 \%$ in the early 1980 s to $5 \%$ in confectionery oils and 2\% in edible oils in 2018 [21], and installation of nutrition signs and nutrition labels on the produced foods. One of the stakeholders of this organization said:

"Encouraging the production of health-oriented goods is another existing policy for society to encourage producer, so that the product has a minimum of calories" (P1).

However, some stakeholders believe that there is not enough monitoring by the Food and Drug Organization regarding the production of unhealthy foods.

"The student buys unhealthy food such as chips, puffs, etc. outside of school; and it is the economic abuse in the producer that there is no hesitation in producing unhealthy food" (P18).

\section{Low supportive stakeholders with high power}

These stakeholders are mainly the Ministry of Sports and Youth, the Municipalities, the Secretariat of the Health and Food Safety, the IRIB, and the Student Organization. In the Sports and Youth Organization, less attention has been paid to the young group under 18 . Accordingly, one of the officials of this organization expressed:

"We have sporting programs for all ages in public, but such programs are very rarely arranged for the children and teenagers age groups" (P14).

This stakeholder also cited the inadequate support of the Sports and Youth Organization in this regard:

"We do not have directions and instructions on the prevention of obesity in children and adolescents; hence, little work can be done in this age group" (P14).

The Municipalities have high power in this policy, and their attention to health issues has increased by creating a unit called "citizenship health" and recruitment of nutrition experts in all municipalities of the country in the last decade. Since Municipalities are public and non- governmental organizations, they have a great power in policymaking, though some challenges restrict this power. One of the stakeholders of this organization said:

"We are in charge of urban management and we are obliged to inform the people and create health houses, hold health-related conferences and meetings, and increase PA and healthy eating. We have tried to do so; but at the moment, we do not have a special program for children or adolescents" (P15).

Despite the fact that Municipalities have programs for reducing obesity among adults and their employees interviewed in this study showed a great interest and desire to participate, however, childhood obesity has not been considered specifically. On the other hand, the COP has been ignored in the policies of this organization; insufficient PA facilities and equipment for this age group in the cities, is one of the signs of this claim.

An employee of the Secretariat of the Health and Food Safety expressed that:

"This office collects reports on the health-related
activities of various organizations, and links medical
sciences with other organizations such as the
governor's office, etc. In the case of children, nothing
has been done absolutely" (P21).

Although the Secretariat of the Health and Food Safety is a powerful organization in COP policies, it is completely inactive in preventing childhood obesity.

Regarding the role of IRIB, this organization had important guidelines on health, nutrition, and PA in the form of films and educational programs, but the target group of most of these programs were adults. On the other hand, unhealthy and obesogenic food commercials often target children and adolescents groups; but this organization is reluctant to stop such commercials due to the high amounts of money received from the manufacturers of these unhealthy foods. In this regard, the stakeholders believed that this organization does not play an effective role in preventing childhood obesity, and even in some cases, it blocks the implementation of these policies.

"One of the major problems is that stakeholders such
as radio and television )IRIB) do not collaborate
appropriately" (P 11).

The Student Organization is not a subset of the MoE, and most stakeholders complain about the lack of cooperation and coordination between them, or the health 
system regarding the snacks provided in school buffets. On the other hand, since this organization is also responsible for organizing programs for students' leisure time, it should provide nutritional, educational, and PArelated programs for students based on the structure of Iran; but this has not been fulfilled efficiently.

\section{Stakeholders' participation rate}

The participation of the stakeholders refers to the issues of participants, level of involvement, intensity, timing and goal of participation, in addition to using the available facilities for this policy [22]. Given the importance of stakeholder participation in this policy, the participation rate was divided into four groups as high, medium, low, and without active participation (Fig. 1).

\section{High participation}

The Health Deputy of MoHME and the Office of Community Nutrition Improvement, as well as healthcare providers of Provincial Health Center have a strong interest in participating. The MoHME is involved in policymaking by providing guidelines such as communicating instructions to the centers under its auspices to provide nutrition and healthy lifestyle training to clients, as well as working with other organizations and stakeholders on overweight and obesity screening and lifestyle

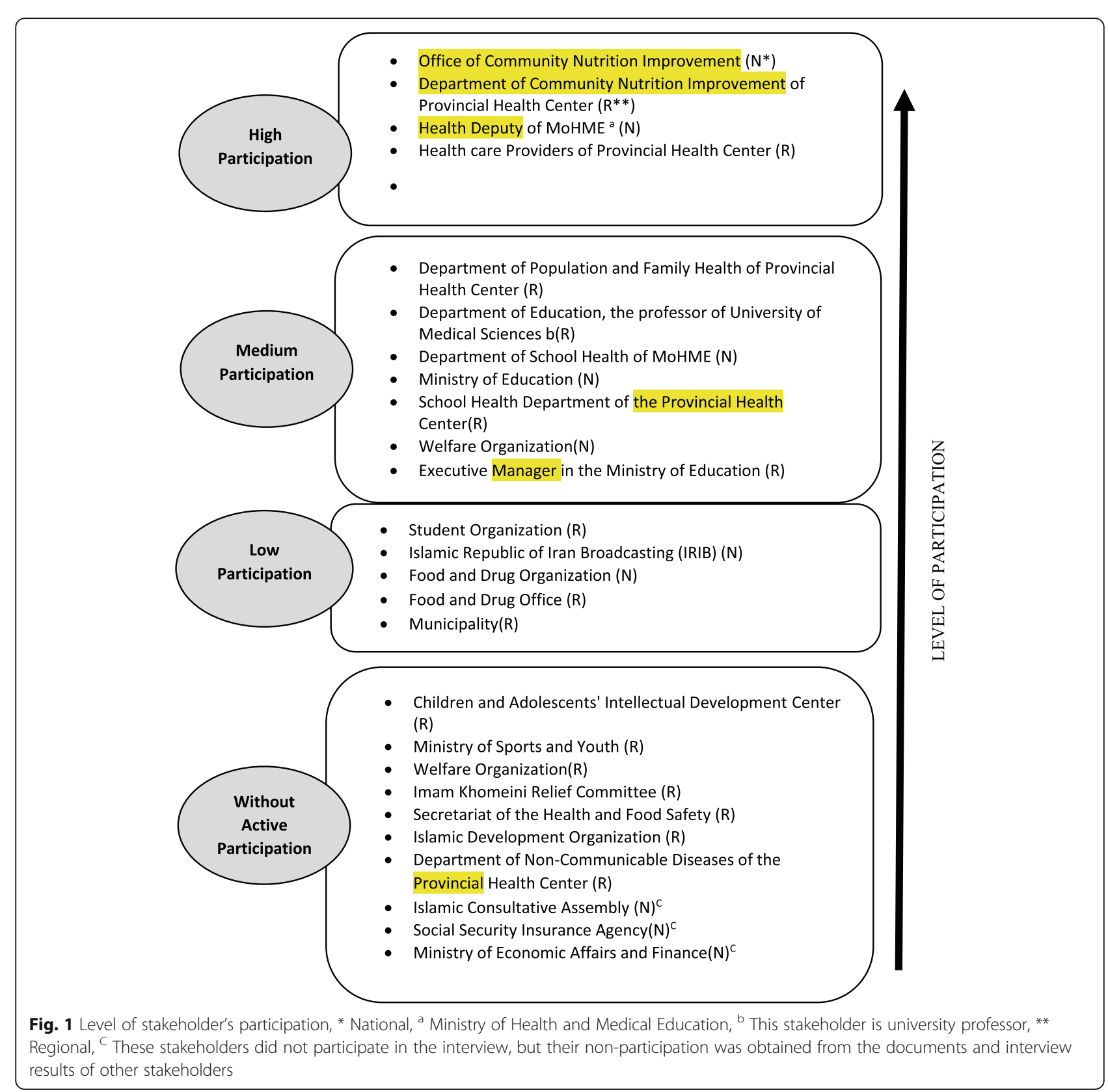


education. The MoHME and its Office of Community Nutrition Improvement were identified as the most important organizations responsible for nutrition issues in Iran. It seemed that these organizations participated through recruitment of nutrition experts and increasing the number of healthcare providers in health centers in recent years. Healthcare providers, had a high participation; but they complained about the multiplicity of tasks assigned to them. They have to do primary healthcare, anthropometry, training nutrition and healthy lifestyle for all age groups, and especially prenatal care, childhood care, as well as management of most non-communicable diseases.

\section{Medium participation}

Some other departments of the MoHME, such as Department of Population and Family Health of Provincial Health Center, Department of School Health of MoHME, and a professor at the University of Medical Sciences who participated in the interview, had medium participation. The level of participation of university professors is limited to the education of health and nutrition students; these people will be responsible for the COP policymaking and implementation in the future. Therefore, their level of participation is high, though the intensity and number of their participants in this field is low. Department of Population and Family Health, in addition to exclusive breastfeeding training, provides brief training on nutrition and physical activity. These stakeholders complained that the COP-related policies are not fully implemented due to the multiplicity of primary healthcare processes, their high workload, and lack of enough time and staff. Nevertheless, the large number of staff involved and their time spent on anthropometry, nutrition and lifestyle education, and low level and intensity of participation in health centers caused these stakeholders to be placed in the group with medium participation.

The Department of School Health is involved as a liaison between schools and health centers; it also holds some health conferences on PA and nutrition. However, the focus of this department is on such processes as prevention of pediculosis and improving oral health, and not COP policies. Although the number of participants in this organization is not large and they have different goals in establishing this relationship, the participation level and intensity of participation related to COP policies is high.

MoE in the policymaking level, as well as executive level in the MoE, despite having high potentials, showed a moderate interest in participating; it seems that they considered COP policies as irrelevant to their scope. Their role is in nutrition education in some grades at school, and also PA education in all grades. However, the results showed that the PA education and implementation is inappropriate. The MoE stakeholders believed that it is difficult to implement some of the educational and executive policies in classrooms. These stakeholders were interested in implementing the policies of their own organizations and they were reluctant to cooperate with other organizations, such as the MoHME programs.

The Welfare Organization was another stakeholder which was reluctant to implement the related policies. Despite the support and cooperation at the policymaking level in this organization, there were many problems at the implementation level. The most important reason identified for these problems in the current study was the lack of financial resources. In this regard, one of the executive managers of this organization announced that:

"First of all, we do not have the budget to implement these policies. Since we are unable to provide enough budget for kindergarten teachers because of the economic problems, it is impossible to expect providing adequate education in kindergarten for children and parents as well as providing quality food and healthy diet for children in rural kindergartens" (P20).

\section{Low participation}

As mentioned earlier, Municipalities can have an indirect impact on COP by holding healthy lifestyle and nutrition education sessions for family adults. Another organization that has a great potential for policymaking in this field is the Ministry of Sports and Youth; however, their policies are mainly focused on youth and adults and not on the people in the age range of $0-18$ years old. They believe that a student's PA should be done in schools and they have no role in this process. Apparently, the Student Organization is involved in implementing COP policies; however, according to most stakeholders in the MoE and MoHME, because this organization is not a subset of $\mathrm{MoE}$, the stakeholders of this organization contract with some obesogenic food producers for financial gain in order to sell their products in student buffets.

Despite the fact that national broadcasting organizations have the strongest potentials to increase health awareness in any society, IRIB was one of the most controversial organizations in COP policies due to the getting huge budgets from the producers of unhealthy foods for advertising their products. In this regard, one of the MoE stakeholders claimed that:

\section{"... but the commercials related to unhealthy foods destroy our efforts (P7)".}

Stakeholders believed that the Food and Drug Organization, despite having great potential to participate 
in COP policies, has not been very active in this area, except for a few cases of reducing sugar and fat in some food products and installation of nutrition signs and labels on produced foods. Therefore, according to other stakeholders, this organization could have been primarily responsible for producing healthier, low-fat, and low-energy foods, which has not been fulfilled. Other stakeholders who have not taken any initiative in this area or have not collaborated with the health system in preventing childhood obesity are classified as stakeholders without active participation (Fig. 1).

\section{Discussion}

In general, the economic, political, social and cultural conditions of any society have potential effects on the health [23]. Considering that the MoHME is the main responsible body for health in Iran, different approaches have been adopted to prevent chronic noncommunicable diseases such as childhood obesity. There have been many changes in recent decades in the Iranian health system; for example, the family physician program started in 2005 [24], and the health transformation plan started in 2014 [25]. Despite improvements in the health system [26], there were adverse effects on overall healthcare policies such as non-communicable disease prevention. Pindus et al. in their study demonstrated that changes in the health system, in addition to having benefits, can also have some adverse effects [27]. Regarding the multidimensional nature of childhood obesity [28], the prevention of obesity in this age group requires a wide inter-sectoral collaboration among stakeholders [29]. The results of the current study showed that coordination between the stakeholders is weak, which can lead to a major problem in policymaking and implementation. A similar result was reported by Adhikari et al., in which the analysis of stakeholders showed that having problems in coordinating between stakeholders would create many problems for health system policies [14]. Another issue is the existence of a top-down approach in the Iranian health system [30], which is not unique to Iran; and this is one of the challenges of the health systems [31]. In a top-down policymaking system, which policymakers do not engage with executive and local stakeholders, in most cases, the desired result is not achieved and may lead to the destruction of the initiatives and policies developed [32].

More focus on curative approach than prevention one in the Iranian health system is another challenge in the policies adopted by the stakeholders. This result was similar to the findings of the study by Doshmangir et al., in which stakeholders believed that the Iranian government was more focused on curative approaches, while, less attention was given to public health and preventive interventions [13]. The results of our study were also similar to the McCollum et al. study, that showed that in Kenya and Indonesia, curative approaches have overcome prevention that have adverse effects on the health system [33]. However, studies have shown that COP is more effective than curative approaches and prevention is the key to success for obesity control [34]. Another issue is that most stakeholders expected that the MoHME would be responsible for policymaking and implementation of COP, but as studies showed, effective interventions in this area require the participation of stakeholders in various sectors. Some of these various sectors stakeholders can include the agriculture section, by allocating subsidies to farmers to produce fruits and vegetables, the education section, by widely using the healthy lifestyle training in the schools and mass media, the existence of appropriate policies in the city for doing PA such as cycling for children and adolescents or creating safe crossings for walking [30,35], and fundamental changes in lifestyle [36]. In 2015, the study by AbuOmar et al. [37] showed that PA-friendly environments are one of the important facilitators for COP. The challenges such as inappropriate programs in the Sports and Youth Organization for this age group, inadequacy of sports equipment in the schools and physical education teachers in primary schools, and inadequate time of physical education courses (less than $1.5 \mathrm{~h}$ per week) were the major problems in policymaking for the PA of children and adolescents. Although, many studies have shown that school-based COP policies have shown the best results [38-40], the approved PA hours for schools in Iran is $2 \mathrm{~h} /$ week, which is equivalent to $7.5 \%$ of the total curriculum, which is low compared to most countries where they have an average of $2.3 \mathrm{~h} /$ week of PA (equivalent to $9 \%$ of the total curriculum) [41]. It should be noted that the amount of PA in schools is actually less than $2 \mathrm{~h}$ per week. Another obstacle to PA in schools is the small size of schoolyards, which is often seen in private schools. This result is similar to the findings of Moges et al., in which about one-half of private schools in Addis Ababa, Ethiopia, had inadequate play area in the private schools, which was significantly associated with overweight/obesity [42].

Some non-governmental organizations (NGOs) involved in this policy, such as the Student Organization, despite their high potential, did not show adequate participation in advancing COP policies. Some studies have showed that most NGO activities in Iran have been performed in the area of providing services, and few of them are related to policymakers [30]. The main NGO in this field is the Student Organization, which unfortunately, plays a negative role in advancing COP policies in Iran. Although this NGO is the principal trustee of school buffets, it does not have proper policies to control school buffets and contract with certain food manufacturers 
whose products are obesogenic. Similar to the study by Louise et al. [43], fast food and soft drink taxing was regarded as a suitable intervention by some stakeholders. Unhealthy food advertising is one of the most important contextual challenges for which appropriate policies have not been developed or implemented. According to the Institute for Fiscal Studies, half of television advertisements for food and drink seen by children are related to products with high levels of fat, salt, or sugar. Unhealthy food advertising has been shown to be one of the obstacles to the implementation of COP policies in most studies [44-46].

Accordingly, the Iranian parliament can contribute in related legislation such as taxing unhealthy and obesogenic foods, allocating subsidies for healthy foods, and allocating funds for the free distribution of healthy foods in schools; but most stakeholders complained about the government's insufficient support for this policy. However, in a study in the United Kingdom entitled "Healthy Weight, Healthy Lives (HWHL)" to prevent obesity, a stakeholder analysis of the program showed that success in such programs was due to government stakeholders direct participation and support as well as timely financing by relevant stakeholders [29]. Another French study called, 'Ensemble Prévenons l'ObésitéDes Enfants' (EPODE), showed that by involving different stakeholders in various fields, significant achievements were made in the implementation of these policies.

\section{Conclusion}

According to our results, the following were among the main challenges of COP policies in Iran, some of which can be generalized to other countries: disconnect between COP policies, implementation, and stakeholders; less attention to prevention approach than curative one; and high advertising of unhealthy foods. Other challenges include insufficient budget allocation to implement COP policies, not classifying age groups in the policymaking, and less attention to the age group under 18 years. Future issues such as delegating student buffet authority to a non-governmental organization and the non-use of existing powers and resources by most stakeholders, demonstrate the fundamental need for advocacy in this area.

\section{Abbreviations \\ CASPIAN: Childhood and Adolescence Surveillance and Prevention of Adult Non-Communicable Disease; COP: Childhood Obesity Prevention; \\ ECHO: Ending Childhood Obesity; HWHL: Healthy Weight, Healthy Lives; IRIB: Islamic Republic of Iran Broadcasting; MoE: Ministry of Education; MoHME: Ministry of Health and Medical Education; WHO: World Health Organization}

\section{Acknowledgments}

This research was part of a Ph.D thesis project, belonged to Shahnaz Taghizadeh, coded as IR.TBZMED.REC.1398.840 which has been approved by the ethics committee of Tabriz University of Medical Sciences in Tabriz, Iran (Grant number: 62918). We are grateful to the Tabriz University of Medical Sciences and their financial support and all of the stakeholders.

\section{Authors' contributions}

SHT, RKH, and MAF, designed the study. MAF and RKH supervised the project. SHT wrote the first draft of manuscript. SHT conducted the analyses. MAF and RKH were also involved in manuscript revision. All authors contributed to writing, revising, and approved the final manuscript.

\section{Funding}

This work was supported by Tabriz University of Medical Sciences (Grant number: IR.TBZMED.REC.1398.840).

\section{Availability of data and materials}

The datasets used and/or analyzed during the current study are available from the corresponding author on reasonable request.

\section{Declarations}

Ethics approval and consent to participate

This study was approved by the Ethics Committee of Tabriz University of Medical Sciences (IR.TBZMED.REC.1398.840). Participants were provided information about the study and consented by proceeding to take the survey.

\section{Consent for publication}

Not applicable.

\section{Competing interests}

The authors have no conflicts of interest.

\section{Author details}

${ }^{1}$ Student Research Committee, Faculty of Nutrition, Tabriz University of Medical Sciences, Tabriz, Iran. ${ }^{2}$ Department of Health Policy and Management, School of Management and Medical Informatics, Tabriz University of Medical Sciences, Tabriz, Iran. ${ }^{3}$ Department of Community Nutrition, Nutrition Faculty, Tabriz University of Medical Sciences, POBOX: 14711, Attar Nishabouri St., Tabriz 5166614711, Iran.

Received: 23 September 2020 Accepted: 4 March 2021

Published online: 17 March 2021

\section{References}

1. Daniels S. Complications of obesity in children and adolescents. Int J Obes. 2009;33(1):S60-5.

2. Kuczmarski R, et al. CDC growth charts: United States. Adv Data. 2000; 314:1-27.

3. Hammersley ML, et al. An internet-based childhood obesity prevention program (Time2bHealthy) for parents of preschool-aged children: randomized controlled trial. J Med Internet Res. 2019;21(2):e11964.

4. Motlagh $\mathrm{M}$, et al. Methodology and early findings of the fifth survey of childhood and adolescence surveillance and prevention of adult noncommunicable disease: the Caspian-v study. Int J Prev Med. 2017; 8(1):4-4.

5. Madadizadeh $F$, et al. Using advanced statistical models to predict the nonCommunica $\neg$ ble diseases. Iran J Public Health. 2015;44(12):1714-5.

6. Mousavi SM, Anjomshoa M. Prevention and control of non-communicable diseases in Iran: a window of opportunity for policymakers. Iran J Public Health. 2014;43(12):1720

7. McGee, M., Childhood obesity: the importance of diet and physical activity. Health Science Inquiry, 2018. 9(1): p. 39-Page 40.

8. Taghizadeh S, Alizadeh M. The role of lipids in the pathogenesis of metabolic syndrome in adolescents. Exp Clin Endocrinol Diabetes. 2018; 126(01):14-22.

9. Norris E, et al. Physically active lessons in schools and their impact on physical activity, educational, health and cognition outcomes: a systematic review and meta-analysis. Br J Sports Med. 2020;54(14):826-38.

10. Heshmat $\mathrm{R}$, et al. Metabolic syndrome and associated factors in Iranian children and adolescents: the CASPIAN-V study. J Cardiovasc Thorac Res. 2018;10(4):214.

11. WHO. Population-based prevention strategies for childhood obesity: report of a WHO forum and technical meeting, Geneva, 15-17. Deceember 2009. 2010 [cited 2020 7/27/2020]; Available from: https://www.who.int/dietphysicala ctivity/childhood/child-obesity-eng.pdf. 
12. Goldberg DS. The shadows of sunlight: why disclosure should not be a priority in addressing conflicts of interest. Public Health Ethics. 2019;12(2): 202-12.

13. Doshmangir $L$, et al. Policy analysis of the Iranian health transformation plan in primary healthcare. BMC Health Serv Res. 2019;19(1):1-8.

14. Adhikari $R$, et al. Foreign aid, Cashgate and trusting relationships amongst stakeholders: key factors contributing to (mal) functioning of the Malawian health system. Health Policy Plan. 2019;34(3):197-206.

15. Ahmad SR, Schubert L, Bush R. Government and school community member perception on childhood obesity prevention in the primary school settings of Brunei Darussalam. J Health Sci. 2018;8(3):181-8.

16. Schmeer, K., Stakeholder analysis guidelines. Policy Toolkit for strengthening health sector reform, 1999. 1.

17. The exact number of Iranian cities in 2016, [Persia]. 2020; Available from: https://www.irna.ir/news/81645518/.

18. Municipalities and Villages Organization of the country, available from http://imo.org.ir/RContent/1TIQBX-.aspx, 2019. 2020.

19. Bahrainy $H$, Khosravi $H$. The impact of urban design features and qualities on walkability and health in under-construction environments: the case of Hashtgerd new town in Iran. Cities. 2013;31:17-28.

20. Pouraram, $H_{\text {., }}$ et al., Successful decreases of malnutrition among children in Islamic Republic of Iran in the past two decades. 2014.

21. Food and Drug Administration, Tehran.Iran. Criterion of health and hygienic properties of edible seeds and fruits, edible oils and fats (Persian). 2018 [cited 2020; Available from: https://www.fda.gov.ir/OldFiles/e094305627b72 de87b4274eb2b12c590.pdf.

22. Teder $M$, Kaimre $\mathbf{P}$. The participation of stakeholders in the policy processes and their satisfaction with results: a case of Estonian forestry policy. Forest Policy Econ. 2018;89:54-62

23. Chitewere $T$, et al. How neighborhoods influence health: lessons to be learned from the application of political ecology. Health Place. 2017;45:117-23.

24. Khayatzadeh-Mahani, A. and A. Takian, Family physician program in Iran: considerations for adapting the policy in urban settings. Arch Iran Med, 2014. 17(11): p. 0-0.

25. Mosadeghrad AM, et al. The impact of health transformation plan on health services fees: brief report. Tehran Univ Med J TUMS Public. 2018, 76(4):277-82.

26. Tabrizi JS, Pourasghar F, Nikjoo RG. Status of Iran's primary health care system in terms of health systems control knobs: a review article. Iran J Public Health. 2017;46(9):1156.

27. Pindus, N.M., The effects of health care industry changes on health care workers and quality of patient care: summary of literature and research. 1997.

28. Vyas, N., et al., Childhood Obesity and Diabetes: Role of Probiotics and Prebiotics, in Global Perspectives on Childhood Obesity. 2019, Elsevier. p. 363-376.

29. Hawkes C, Ahern AL, Jebb SA. A stakeholder analysis of the perceived outcomes of developing and implementing England's obesity strategy 2008-2011. BMC Public Health. 2014;14(1):441.

30. Khodayari-Zarnaq R, et al. Comprehensive analysis of the HIV/AIDS policymaking process in Iran. Health Res Policy Syst. 2019;17(1):69.

31. Duffield C, et al. Uncovering the disconnect between nursing workforce policy intentions, implementation, and outcomes: lessons learned from the addition of a nursing assistant role. Policy Politics Nurs Pract. 2019;20(4): 228-38

32. Leach M. Pathways to sustainability in the forest? Misunderstood dynamics and the negotiation of knowledge, power, and policy. Environ Plan A. 2008; 40(8):1783-95

33. McCollum $\mathrm{R}$, et al. Health system governance following devolution: comparing experiences of decentralisation in Kenya and Indonesia. BMJ Glob Health. 2018;3(5):e000939.

34. Pandita A, et al. Childhood obesity: prevention is better than cure. Diabetes Metab Syndr Obes. 2016;9:83

35. SHAHRZAD MK. Policy priorities of the IR of IRAN for childhood obesity prevention. IJEM. 2017;18(6):403-11

36. Richardson, E., The Role of Public Health Organizations in Addressing Public Health Problems in Europe: The Case of Obesity Alcohol and Antimicrobial Resistance. 2018: World Health Organization.

37. Abu-Omar K, et al. Barriers, facilitators and capacities for childhood obesity prevention in 12 European Union member states: results of a policy-maker survey. Public Health Panor. 2018;4(03):360-7.
38. Taghizadeh S, Farhangi MA. The effectiveness of pediatric obesity prevention policies: a comprehensive systematic review and dose-response meta-analysis of controlled clinical trials. J Transl Med. 2020;18(1):1-21.

39. Bleich SN, et al. Systematic review of community-based childhood obesity prevention studies. Pediatrics. 2013;132(1):e201-10.

40. Centers for Disease Control and Prevention, C.H.S., available from https:// www.cdc.gov/healthyschools/health_and_academics/index.htm. (Accessed 5 Oct 2020).

41. Ismaili Mohammad Reza, e.a., Comparative study of physical education curriculum in Iran and selected countries, 2005,. Harekat (persian), 2005. 69: p. 28-86.

42. Moges $\mathrm{T}$, et al. Is inadequate play area in schools associated with overweight among students in Addis Ababa, Ethiopia? A comparative crosssectional study. Epidemiol Health. 2018;40.

43. Signal LN, et al. Appetite for health-related food taxes: New Zealand stakeholder views. Health Promot Int. 2018;33(5):791-800.

44. Pourmoradian S, et al. Television food advertisements and childhood obesity: a systematic review. Int J Vitam Nutr Res. 2020;1:7.

45. Li D, et al. The extent and nature of television food advertising to children in Xi'an, China. BMC Public Health. 2016:16(1):770.

46. Montaña M, Jiménez-Morales $M$, Vàzquez M. Food advertising and prevention of childhood obesity in Spain: analysis of the nutritional value of the products and discursive strategies used in the ads Most viewed by children from 2016 to 2018. Nutrients. 2019;11(12):2873.

\section{Publisher's Note}

Springer Nature remains neutral with regard to jurisdictional claims in published maps and institutional affiliations.

Ready to submit your research? Choose BMC and benefit from:

- fast, convenient online submission

- thorough peer review by experienced researchers in your field

- rapid publication on acceptance

- support for research data, including large and complex data types

- gold Open Access which fosters wider collaboration and increased citations

- maximum visibility for your research: over $100 \mathrm{M}$ website views per year

At $\mathrm{BMC}$, research is always in progress.

Learn more biomedcentral.com/submissions 